\title{
NONTRANSPLANT CARDIAC SURGERY FOR END-STAGE CARDIOMYOPATHY
}

Hisayoshi Suma, MD

Tadashi Isomura, MD

Taiko Horii, MD

Toru Sato, MD

Norio Kikuchi, MD

Ken Iwahashi, MD

Joji Hosokawa, MD
Objective: To treat end-stage cardiomyopathy, we evaluated endoventricular circular patch plasty, partial left ventriculectomy, and valvular reconstruction alone in our 2-year experience.

Methods: Among 86 patients with heart failure evaluated between December 1996 and February 1999, 33 patients with ischemic cardiomyopathy (25 men and 8 women; mean age $61 \pm 7.8$ years; New York Heart Association class $3.5 \pm 0.5)$ were treated with endoventricular circular patch plasty combined with coronary bypass grafting $(84 \%)$ and mitral reconstruction $(36 \%)$. The other 53 patients with nonischemic cardiomyopathy (45 men and 8 women; mean age $48 \pm 14.3$ years, New York Heart Association class $3.7 \pm 0.5$ ), were treated by left ventricular reduction by partial left ventriculectomy $(n=37)$ or patch plasty $(n=3)$ and valve reconstruction alone $(n=13)$. The first 24 patients (group I) underwent ventriculectomy with or without valve reconstruction; the more recent 29 patients (group II) underwent left ventricular reduction $(n=16)$ or valve reconstruction alone $(n=13)$ on the basis of the intraoperative echocardiographic evaluation to observe changes of wall motion and thickness during cardiopulmonary bypass.

Results: Ischemic group: Hospital mortality in elective $(\mathrm{n}=26)$ and emergency $(n=7)$ operations was $4 \%$ and $43 \%$, and 3 patients died in the late postoperative period. Mean New York Heart Association class and ejection fraction improved from $3.5 \pm 0.5$ to $1.5 \pm 0.7$ and from $23 \% \pm 7.7 \%$ to $36 \%$ $\pm 8.6 \%$, respectively. Left ventricular end-diastolic and end-systolic volume indexes decreased from $162 \pm 46 \mathrm{~mL} / \mathrm{m}^{2}$ to $110 \pm 39 \mathrm{~mL} / \mathrm{m}^{2}$ and from 130 $\pm 47 \mathrm{~mL} / \mathrm{m}^{2}$ to $70 \pm 32 \mathrm{~mL} / \mathrm{m}^{2}$, respectively. Nonischemic group: In 40 patients with left ventricular reduction, hospital mortality in elective $(n=33)$ and emergency $(\mathrm{n}=7)$ operations was $6 \%$ and $86 \%$, and 5 patients died in the late postoperative period. Mean New York Heart Association class and ejection fraction improved from $3.7 \pm 0.5$ to $1.7 \pm 0.6$ and from $18 \% \pm 6.4 \%$ to $31 \% \pm 5.9 \%$. Left ventricular end-diastolic and end-systolic volume indexes decreased from $203 \pm 45 \mathrm{~mL} / \mathrm{m}^{2}$ to $110 \pm 37 \mathrm{~mL} / \mathrm{m}^{2}$ and from 164 $\pm 40 \mathrm{~mL} / \mathrm{m}^{2}$ to $79 \pm 33 \mathrm{~mL} / \mathrm{m}^{2}$, respectively. In 13 patients undergoing valve reconstruction alone (12 mitral with or without tricuspid and 1 tricuspid plus left ventricular assist device), hospital mortality in elective $(n=9)$ and emergency $(n=4)$ operations was $0 \%$ and $50 \%$ with no late deaths. Mean New York Heart Association class and ejection fraction improved from $3.6 \pm 0.5$ to $2.0 \pm 0.5$ and from $22 \% \pm 6.0 \%$ to $30 \% \pm 14.5 \%$, respectively. Mean left ventricular end-diastolic and end-systolic volume indexes decreased from $170 \pm 34 \mathrm{~mL} / \mathrm{m}^{2}$ to $150 \pm 50 \mathrm{~mL} / \mathrm{m}^{2}$ and from $140 \pm 38 \mathrm{~mL} / \mathrm{m}^{2}$ to $104 \pm 40$
From the Departments of Cardiovascular Surgery, Anesthesiology, and Cardiology, ${ }^{\mathrm{b}}$ Shonan Kamakura General Hospital, Kanagawa, Japan.

Read at the Seventy-ninth Annual Meeting of The American Association for Thoracic Surgery, New Orleans, La, April 18-21, 1999.

Received for publication April 22, 1999; revisions requested Aug 23, 1999; revisions received Oct 25, 1999; accepted for publication Feb 16, 2000.
Address for reprints: Hisayoshi Suma, MD, Division of Cardiothoracic Surgery, Hayama Heart Center, 1898, Hayama, Kanagawa 2400166, Japan (E-mail: HisaSuma@ NetLaputa.ne.jp).

J Thorac Cardiovasc Surg 2000;119:1233-45

Copyright $\odot 2000$ by The American Association for Thoracic Surgery $0022-5223 / 2000 \$ 12.00+0 \quad \mathbf{1 2 / 6 / 1 0 6 5 2 0}$

doi: $10.1067 / \mathrm{mtc} .2000 .106520$ 
$\mathrm{mL} / \mathrm{m}^{2}$, respectively. Overall mortality decreased from $50 \%$ in group I to $10 \%$ in group II. The survival estimates at 2 years were $77 \%$ (confidence limits 57\%-88\%) in the ischemic group and 63\% (confidence limits $47 \%$ $75 \%$ ) in the nonischemic group (no significant difference). The analysis of our data showed that the factors influencing the surgical results for dilated cardiomyopathy were presence of severe mitral regurgitation, preoperative New York Heart Association functional class IV with emergency operation, and operative procedures with randomly performed partial left ventriculectomy without an intraoperative echo test.

Conclusion: Endoventricular circular patch plasty, partial left ventriculectomy, and solo valve reconstruction can be performed with an acceptably low risk as elective operations. The selection of operative procedures in idiopathic dilated cardiomyopathy and avoidance of emergency surgery improved operative mortality and morbidity. Among patients who survived at least 1 year, there were no late deaths up to 30 months' follow-up. (J Thorac Cardiovasc Surg 2000;119:1233-45)

C ardiac transplantation is an established treatment for end-stage heart failure. However, it is not widely available because of a shortage of donors and, in parts of the world, societal limitations. In the search for an effective nontransplant cardiac operation to treat end-stage cardiomyopathy, partial left ventriculectomy (PLV),, 2 endoventricular circular patch plasty (EVCPP), ${ }^{3}$ and mitral annuloplasty alone ${ }^{4}$ have recently been clinically investigated. We report our 2-year experience with these procedures.

\section{Patients and methods}

From December 1996 to February 1999, 86 patients (70 men and 16 women, mean age 54 years, range $14-79$ years) with ischemic and nonischemic dilated cardiomyopathy were surgically treated at Shonan Kamakura General Hospital. All patients had signs of New York Heart Association (NYHA) class III or IV heart failure with a dilated, poorly functioning left ventricle. Sixty-seven (78\%) patients of them were considered to be candidates for heart transplantation, and 46 in the 67 patients were either more than 70 years old or had severe pulmonary hypertension before the operation.

Ischemic cardiomyopathy group. Ischemic cardiomyopathy was defined as a nonaneurysmal, diffusely akinetic left ventricle with chronic heart failure after myocardial infarction. Among 58 patients undergoing EVCPP for postinfarction left ventricular dysfunction in the same period, we enrolled 33 patients in the ischemic cardiomyopathy group by excluding those with a dyskinetic or akinetic left ventricle with large scar clearly bordered with well-functioning myocardium.

The group comprised 25 men and 8 women with a mean age of 61 years, ranging from 48 to 79 years. All patients had signs of congestive heart failure-NYHA class III in 17 patients and class IV in 16 patients. Six patients had mild angina pectoris before the operation but the others did not have chest pain. Among 16 patients in NYHA class IV,
7 required inotropic support (status 1). Seven patients had ongoing shock and required emergency surgery. All patients had a large anteroseptal myocardial infarction with or without a posterolateral or inferior infarction. Coronary angiography showed single vessel disease (anterior descending artery) in 2 patients, double vessel disease in 7 patients, triple vessel disease in 20 patients, and left main trunk disease with a distal coronary artery lesion in 4 patients. Mitral regurgitation was noted in 12 patients $(36 \%)$ and tricuspid regurgitation in 4 patients. Preoperative characteristics of the patients and their left ventricles are summarized in Table I and Fig 1.

Surgical technique. During normothermic cardiopulmonary bypass (CPB) with antegrade warm blood cardioplegia, coronary artery bypass grafting (CABG) or mitral repair was performed first and then the left ventricle was opened. While observing the left ventricle closely, we placed an endocardial 2-0 Prolene purse-string suture (Ethicon, Inc, Somerville, NJ) along the border between the akinetic and kinetic areas, as Dor described. ${ }^{5}$ The border between the akinetic and kinetic areas was sometimes difficult to define because there is no clear scar in the left ventricle in ischemic cardiomyopathy. We assessed it by palpation of the left ventricle with the open beating heart technique by aortic declamping. The purse-string suture was pulled and tied, and then the remaining opening was closed with a Dacron patch attached with a continuous 2-0 Prolene suture. Finally, the excluded akinetic left ventricular wall was closed to avoid postoperative bleeding (Fig 2).

CABG was performed in 31 patients $(94 \%)$ with a mean number of $3.1 \pm 1.2$ distal anastomoses per patient. The anterior descending artery was graftable in 26 patients, although it was not clearly visualized in preoperative angiograms in many cases. A mitral valve operation was concomitantly performed in 12 patients, with 8 valve repairs and 4 replacements. Tricuspid annuloplasty was added in 4 patients. The mean durations of aortic crossclamping and $\mathrm{CPB}$ were $75 \pm$ 36 minutes and $135 \pm 54$ minutes, respectively. 

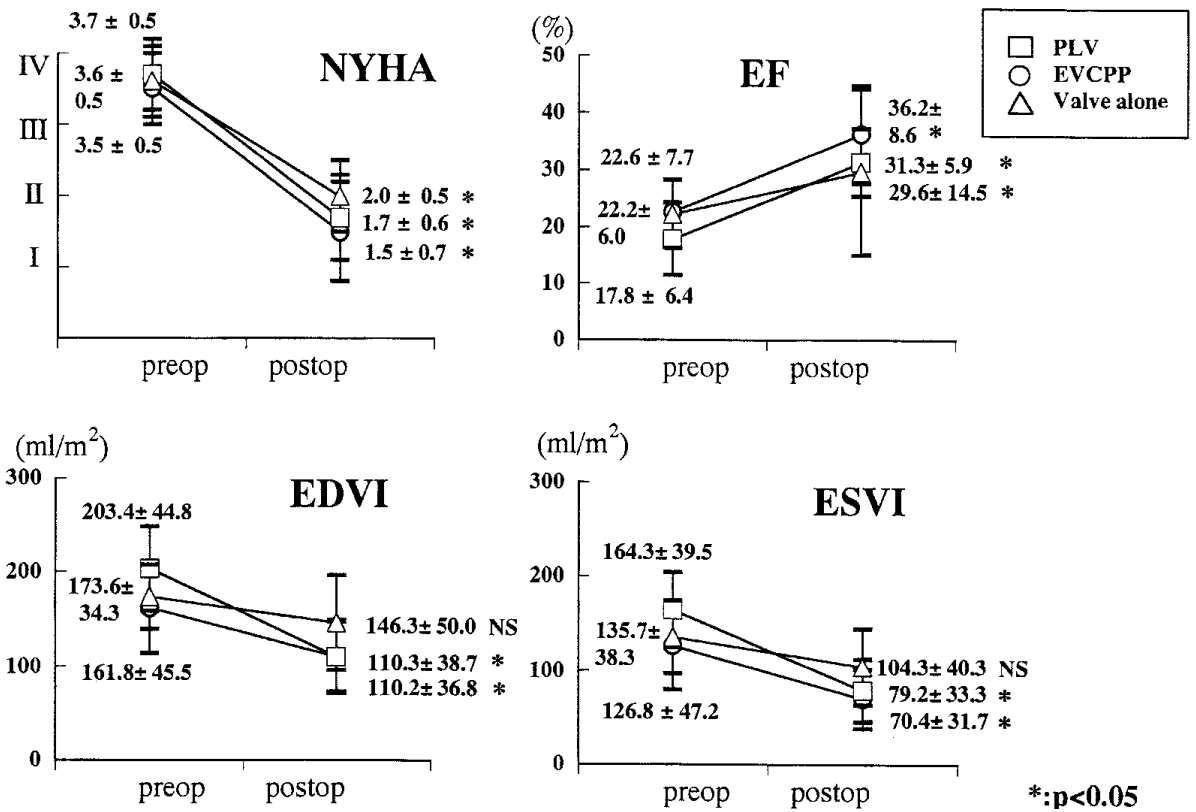

Fig 1. Changes in NYHA class and left ventricular parameters before and after the operation. EF, Ejection fraction; $E D V I$, end-diastolic volume index; $E S V I$, end-systolic volume index; NS, not significant; $E V C P P$, endoventricular circular patch plasty; $P L V$, partial left ventriculectomy.

Table I. Preoperative characteristics

\begin{tabular}{|c|c|c|c|c|}
\hline & \multicolumn{4}{|c|}{ Type of cardiomyopathy/type of procedure } \\
\hline & \multirow{3}{*}{$\begin{array}{c}\text { Ischemic } \\
E V C P P \pm C A B G / v a l v e\end{array}$} & \multicolumn{3}{|c|}{ Nonischemic } \\
\hline & & \multirow{2}{*}{$\begin{array}{c}\text { Group I } \\
\text { LV reduction } \pm \text { valve }\end{array}$} & \multicolumn{2}{|c|}{ Group II } \\
\hline & & & $L V$ reduction & Valve alone \\
\hline No. of patients & 33 & 24 & 16 & 13 \\
\hline Age $(y)$ & $61(48-79)$ & $48(14-67)$ & $48(38-70)$ & $51(16-72)$ \\
\hline$P$ value & - & $<.001^{*}$ & $.001^{*}$ & $.008^{*}$ \\
\hline NYHA III/IV (inotropic agents) & $17 / 16(7)$ & 7/17 (14) & $8 / 8(6)$ & 6/7 (5) \\
\hline Ejection fraction $(\%)$ & $22.6 \pm 7.7$ & $18.4 \pm 6.7$ & $16.9 \pm 4.7$ & $22.2 \pm 6.0$ \\
\hline$P$ value & - & .02 & .3 & .9 \\
\hline Diastolic dimension (mm) & $68.9 \pm 10.3$ & $77.0 \pm 6.4$ & $84.0 \pm 8.8$ & $75.1 \pm 6.2$ \\
\hline$P$ value & - & $<.001^{*}$ & $<.001^{*}$ & .06 \\
\hline End-diastolic volume index $\left(\mathrm{mL} / \mathrm{m}^{2}\right)$ & $161.8 \pm 45.5$ & $194.6 \pm 40.8$ & $216.6 \pm 43.3$ & $173.6 \pm 34.3$ \\
\hline$P$ value & - & $.001^{*}$ & $<.001^{*}$ & .4 \\
\hline End-systolic volume index $\left(\mathrm{mL} / \mathrm{m}^{2}\right)$ & $126.8 \pm 47.2$ & $158.3 \pm 38.9$ & $176.3 \pm 34.4$ & $135.7 \pm 38.3$ \\
\hline$P$ value & - & $<.001^{*}$ & $<.001^{*}$ & .4 \\
\hline
\end{tabular}

$P$ value: Nonischemic group is compared with ischemic group. $E V C P P$, Endoventricular circular patch plasty; $C A B G$, coronary artery bypass grafting; $L V$, left ventricular; NYHA, New York Heart Association.

Nonischemic cardiomyopathy group. This group comprised 53 patients (45 male and 8 female patients, mean age $49 \pm 14$ years, range 14-72 years) with NYHA class III in 19 patients $(36 \%)$ and class IV in 34 patients $(64 \%)$. Mean duration of heart failure was $54 \pm 37$ months. Twenty-five patients (47\%) were supported by intravenous inotropic drugs and 2 patients required intra-aortic balloon pumping before the operation. Eleven patients (20\%) needed emergency surgery because of severe pulmonary edema with hypotension in 8 and cardiac arrest in 3 .

The etiology of cardiomyopathy was noted to be idiopathic dilated cardiomyopathy in 41 patients (77\%), dilated hypertrophic cardiomyopathy in 2 patients, valvular in 7 patients, and arrhythmogenic right ventricular dysplasia, sar- 


\section{Endoventricular Circular Patch Plasty

\author{
Circular
}

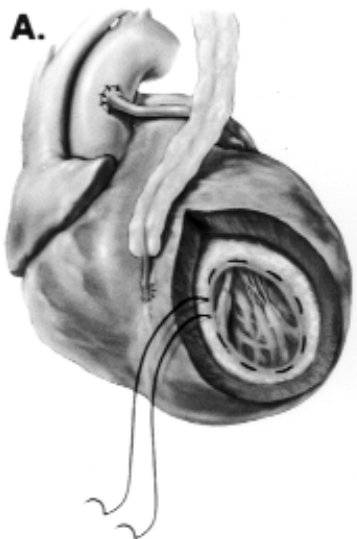

c.
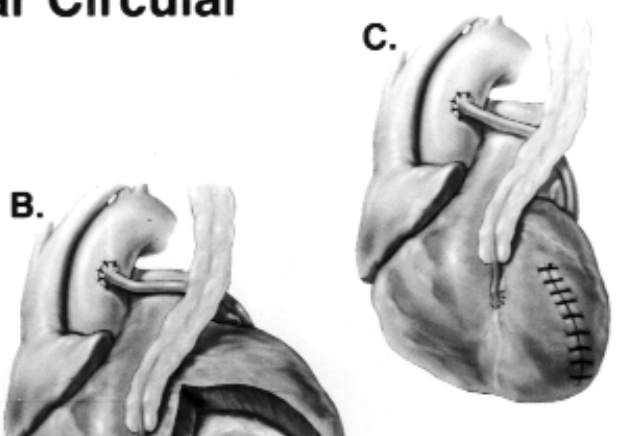

Fig 2. Scheme of endoventricular circular patch plasty (EVCPP). A, A left ventricular incision is made along the anterior descending artery from the apex, and a purse-string suture is placed between the akinetic and kinetic areas. $\mathbf{B}$, The purse-string suture is pulled and tied. The remaining opening is closed with a Dacron patch. C, Finally, the excluded left ventricular wall is closed to avoid bleeding.

coidosis, and corrected transposition of great arteries in 1 patient each.

Regarding surgical strategy, we initially nonselectively performed PLV with or without mitral valve reconstruction as a primary choice in 24 consecutive patients (group I). Papillary muscles were sometimes included for wide excision to achieve strict downsizing of the left ventricle in this group. Then we tried to find the proper site for excision to avoid excessive ventriculectomy by introducing an intraoperative echo-guided volume reduction test.

The basic concept of the volume reduction test is that changes of left ventricular wall motion and thickness can be seen by echocardiography (HP SONOS 5500, HewlettPackard Company, Andover, Mass) before performing the ventriculotomy when the left ventricle is decompressed during $\mathrm{CPB}$, because wall tension may decrease. By decompressing the left ventricle, we could see that the akinetic part becomes kinetic, that is, increased kinetic zones of colors, with increased wall thickness. When a certain area stays thin and akinetic under this condition, we decide to perform PLV or EVCPP depending on the site of akinesis. On the other hand, when the entire left ventricle becomes kinetic, we decide to perform valve reconstruction alone without PLV (Fig 3).

In the latter 29 patients treated with this method (group II), 16 patients underwent left ventricular reduction and the other 13 patients underwent valvular reconstruction alone. Preoperative characteristics of groups I and II are shown in Table I.

In $37(92 \%)$ of the 40 patients having left ventricular reduction (37 PLV and 3 EVCPP), a mitral valve operation was also done, with 26 replacements and 11 repairs. Tricuspid annuloplasty and aortic valve replacement were concomitantly performed in 24 and 4 patients, respectively. Durations of aortic crossclamping and CPB were $73 \pm 30$ minutes and 140 \pm 52 minutes, respectively. Amiodarone $200 \mathrm{mg}$ was routinely given after the operation unless adverse effects appeared.

In 13 patients who underwent valvular operations alone, mitral valve surgery was done in 12 patients with 9 repairs and 3 replacements, and tricuspid valve surgery was combined in 7 patients. The maze procedure was added for 5 patients to treat atrial fibrillation. One patient who was in profound shock was treated with a left ventricular assist device and tricuspid valve replacement. Durations of aortic crossclamping and CPB were $99 \pm 27$ minutes and $162 \pm 29$ minutes, respectively.

Surgical technique. During normothermic CPB, the initial 15 patients were operated on with antegrade warm blood cardioplegia for PLV and mitral valve replacement. After those learning periods, the PLV was performed on the on-pump beating heart without aortic crossclamping, while cardioplegic arrest was used for mitral annuloplasty with an undersized prosthetic ring through the left atriotomy. It is not necessary to make an incision down to the base of the ventricle to extend close to the mitral anulus for PLV. Placing deep and wide mattress sutures (basal tack) without extending the incision is safe and effective (Fig 4). It is important not to leave the dilated base without constriction to obtain effective ejection according to the basal band theory of Torrent-Guasp. ${ }^{6}$ The left ventricle was closed in 2 layers with large-needle 2-0 monofilament sutures (Matsuda Ika Kogyo, Japan) with a bovine strip or Teflon felt if necessary. Tricuspid regurgitation was corrected with the De Vega annuloplasty. 

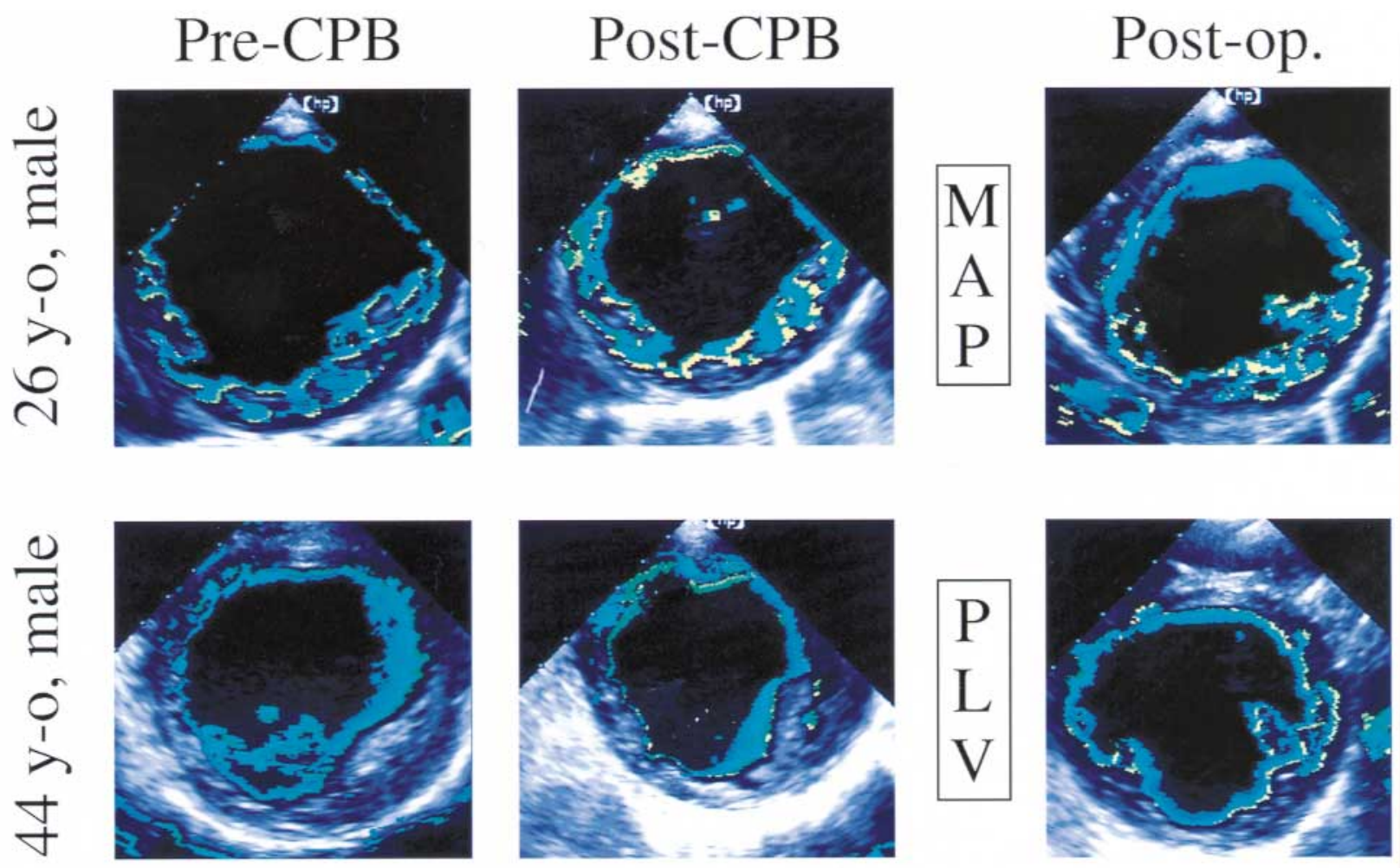

Fig 3. Intraoperative echo-guided volume reduction test used to choose the procedure. During cardiopulmonary bypass $($ Post-CPB) with left ventricular decompression, when the left ventricle increases wall motion and thickness, mitral valve reconstruction $(M A P)$ alone without ventriculectomy is done (top). On the other hand, when an akinetic area remains, partial left ventriculectomy $(P L V)$ is performed (bottom).

Evaluation and follow-up. All patients had preoperative evaluation by cardiac echocardiography. All except very sick patients underwent magnetic resonance imaging, emission beam tomography (Imatron, Inc, South San Francisco, Calif), gated cardiac pool scan, and phase image analysis to assess the left ventricular status before and after the operation. A preoperative catheter ventriculogram was taken when the patient was in relatively stable condition. Dobutamine stress echocardiography was performed in 11 patients, and many others already had inotropic support. Exercise thallium scintigraphy was performed in 18 patients with ischemic cardiomyopathy. A pathologic study was performed in all patients who underwent PLV. A specimen was taken from both the excised left ventricular wall and the ventricular septum.

Follow-up studies were performed in all patients, and the patients received detailed follow-up examinations including cardiac catheterization every 6 months.

Statistical analysis. Continuous variables are expressed as mean \pm SD. Cumulative survivals were calculated by the Kaplan-Meier estimation with the date of operation and the date of most recent follow-up. The differences in the survival were determined by log-rank analysis. A multivariable analysis of independent factors was performed with the Cox proportional hazard model analysis.

\section{Results}

Ischemic cardiomyopathy group. Of the 26 patients who underwent an elective operation, 1 patient (4\%) died in the hospital of a stroke. Late death after discharge from the hospital occurred in 3 patients as a result of arrhythmia, heart failure, and stroke, respectively. Of 7 patients having an emergency operation, 3 patients $(43 \%)$ died of multiorgan failure during hospitalization. No late deaths were noted in this group. The 2-year survival was $77 \%$ (95\% confidence limits 57\%-88\%) (Fig 5). NYHA class improved to class $1.5 \pm 0.7$. Left ventricular end-diastolic or end-systolic volume indexes decreased to $110 \pm 39 \mathrm{~mL} / \mathrm{m}^{2}$ or $70 \pm 32 \mathrm{~mL} / \mathrm{m}^{2}$, respectively, and ejection fraction improved to $36 \% \pm$ 8.6\%, as shown in Fig 1. All parameters improved significantly after the operation $(P<.05)$ (Fig. 6).

Nonischemic cardiomyopathy group. In group I, 2 (12\%) of 17 patients having an elective operation died in the hospital, 1 of pneumonia and the other of heart failure. On the other hand, $6(86 \%)$ of 7 patients with an emergency operation died during hospitalization of heart failure, infection, valvular reoperation, and multi- 


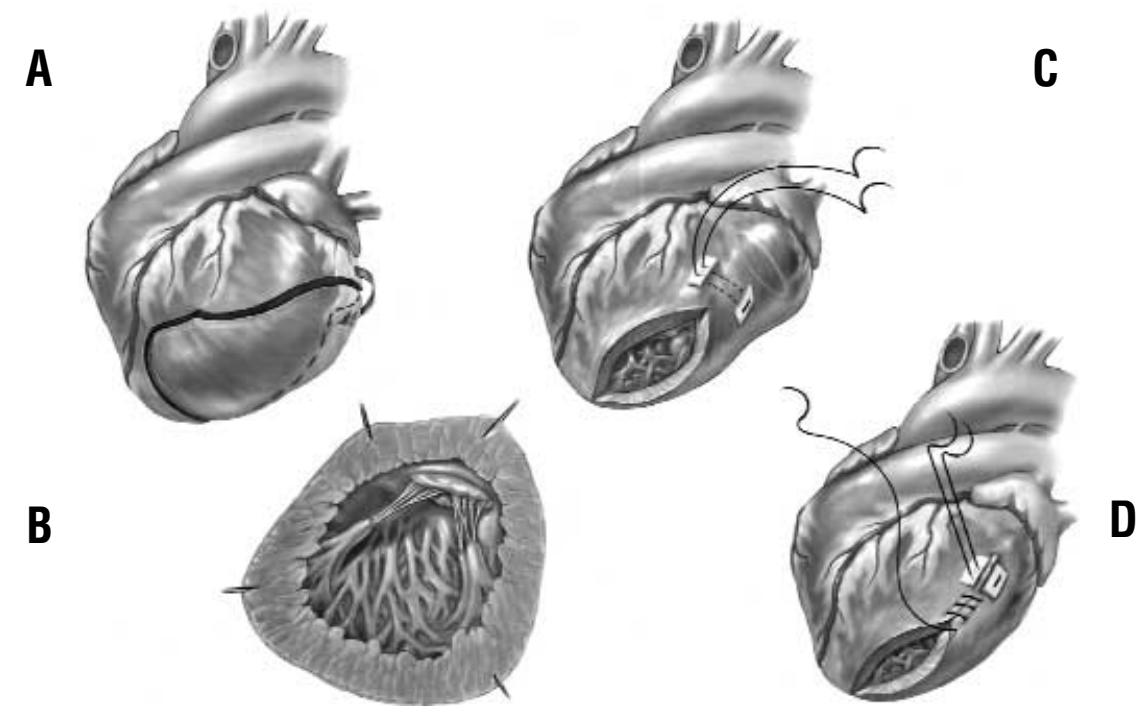

Fig 4. Scheme of partial left ventriculectomy. A, A lateral left ventricular incision is made including the apex. B, Excision does not extend beyond papillary muscles. C, Instead of the incision down to the base close to the mitral anulus, a deep and wide mattress suture (basal tack) is safe and effective. D, The ventriculotomy is closed in 2 layers with continuous sutures.

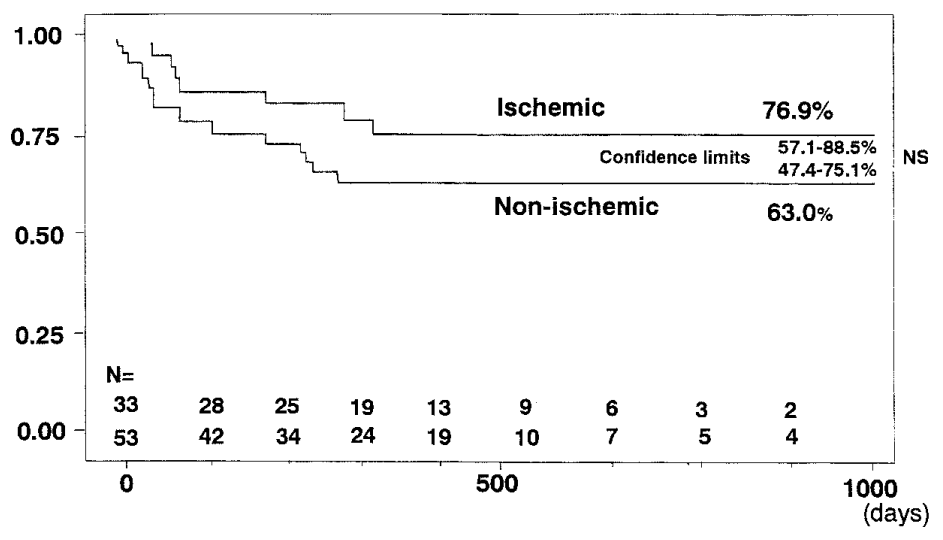

Fig 5. Kaplan-Meier survival estimates. At 2 years, the survival estimate was $77 \%$ (confidence limits $57 \%-88 \%$ ) in patients with ischemic cardiomyopathy and $63 \%$ (confidence limits $47 \%-75 \%$ ) in patients with nonischemic cardiomyopathy after surgery.

organ failure. There were 5 late deaths caused by recurrent heart failure in 2 patients and hepatic failure, prosthetic valve thrombus, and pulmonary tuberculosis in 1 patient each.

In group II, there were no deaths in 25 patients having elective operations and 2 deaths, due to heart failure, in 4 patients having emergency operations. One patient died in the late postoperative period of cancer without heart failure.
Return of heart failure was noted in 4 patients in group I, with 2 deaths, and in 5 patients in group II, with no late deaths. One patient having mitral valve repair alone as the initial operation returned to the hospital with recurrent mitral regurgitation and an enlarged left ventricle. The patient was then successfully treated by mitral valve replacement and PLV (Table II). The survival estimate was 63\% (confidence limits 47\%$75 \%$ ) at 2 years (Fig 5). 
Table II. Surgical results of left ventricular reduction

\begin{tabular}{|c|c|c|c|c|}
\hline & \multirow[b]{2}{*}{$E V C P P \pm C A B G / v a l v e$} & \multirow{2}{*}{$\begin{array}{c}\text { Group I } \\
\text { LV reduction } \pm \text { valve }\end{array}$} & \multicolumn{2}{|c|}{ Group II } \\
\hline & & & $L V$ reduction \pm valve & Valve alone \\
\hline No. & 33 & 24 & 16 & 13 \\
\hline Mortality & $7 / 33$ & $12 / 24$ & $1 / 16$ & $2 / 13$ \\
\hline Hospital + late $(\%)$ & 21.2 & 50.0 & 6.3 & 15.4 \\
\hline IABP/LVAD & $1 / 0$ & $6 / 0$ & $0 / 0$ & $1 / 1$ \\
\hline Return of heart failure & 3 & 4 & 3 & 2 \\
\hline Follow-up (d) & $377 \pm 228$ & $365 \pm 323$ & $272 \pm 109$ & $316 \pm 156$ \\
\hline Median (d) & 362 & 278 & 262 & 368 \\
\hline
\end{tabular}

$\overline{E V C P P}$, Endoventricular circular patch plasty; $C A B G$, coronary artery bypass grafting; $L V$, left ventricular; $I A B P$, intra-aortic balloon pumping; $L V A D$, left ventricular assist device.
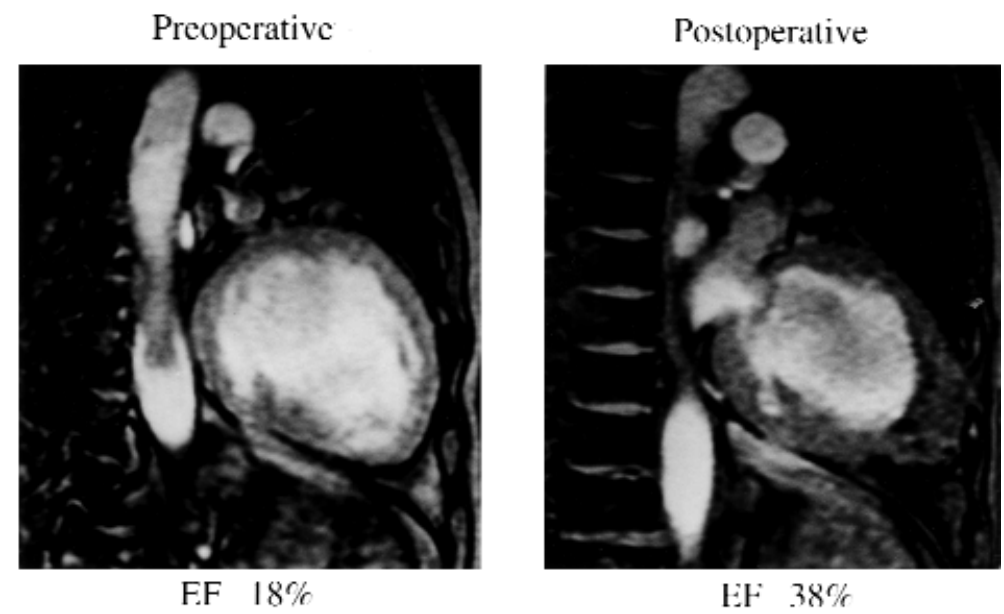

Fig 6. Magnetic resonance imaging ventriculogram before and after endoventricular circular patch plasty for ischemic cardiomyopathy. Ejection fraction $(E F)$ increased from $18 \%$ to $38 \%$ and left ventricular end-diastolic and end-systolic indexes decreased from 194 to $101 \mathrm{~mL} / \mathrm{m}^{2}$ and from 160 to $63 \mathrm{~mL} / \mathrm{m}^{2}$, respectively. New York Heart Association class improved from IV to I in a 64-year-old man.

To summarize the surgical results of left ventricular reduction in nonischemic cardiomyopathy in 40 patients, there were 2 hospital deaths in 33 elective operations and 6 hospital deaths in 7 emergency operations. Overall hospital mortality was $20 \%$, and 5 patients died in the late postoperative period. One- and 2-year survivals were $61 \%$ in all cases, $71 \%$ in elective cases, and $14 \%$ in emergency cases, and there were no deaths 1 year after the operation. NYHA class improved to class $1.7 \pm 0.6$. Left ventricular end-diastolic or end-systolic indexes decreased to $110 \pm 37 \mathrm{~mL} / \mathrm{m}^{2}$ or $79 \pm 33 \mathrm{~mL} / \mathrm{m}^{2}$, respectively, and ejection fraction improved to $31.3 \% \pm 5.9 \%$, as shown in Fig 1. All variables improved significantly after the operation $(P<.05)$ (Fig 7).

Changes of NYHA class and left ventricular parameters are shown in Fig 1. Left ventricular end-diastolic pressure and mean pulmonary capillary wedge pressure decreased significantly from $28 \pm 7.8 \mathrm{~mm} \mathrm{Hg}$ to $21 \pm$ $7.5 \mathrm{~mm} \mathrm{Hg}$ and from $25 \pm 7.6 \mathrm{~mm} \mathrm{Hg}$ to $19 \pm 8.3 \mathrm{~mm}$ $\mathrm{Hg}$, respectively, at 1 postoperative month in 20 patients. Once successful left ventricular reduction had been accomplished, the histogram became close to normal with time (Fig 8). On the other hand, in patients who had recurrent heart failure after the operation, the histogram did not improve regardless of postoperative left ventricular size (postoperative left ventricular dimension ranged from 50 to $76 \mathrm{~mm}$ in 5 patients having return of heart failure) (Fig 9).

Regarding ventricular arrhythmias, 33 patients underwent 24 hours of Holter monitoring before and after PLV. By Lown class assessment, 21 patients $(84 \%)$ were in class IV-b before the operation. The 


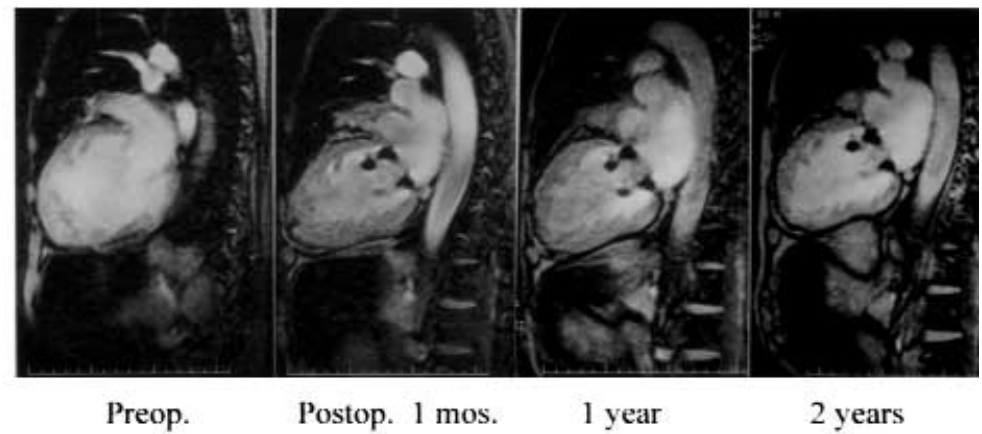

Fig 7. Magnetic resonance imaging ventriculogram before and after partial left ventriculectomy for idiopathic dilated cardiomyopathy. Ejection fraction increased from $18 \%$ to $32 \%$ and left ventricular end-diastolic and endsystolic indexes decreased from 198 to $105 \mathrm{~mL} / \mathrm{m}^{2}$ and from 160 to $71 \mathrm{~mL} / \mathrm{m}^{2}$, respectively. There are no instances of redilatation at 1 and 2 years after the operation. New York Heart Association class improved from class IV with inotropic agents to class I in a 58-year-old man.

condition of 14 patients (42\%) improved, that of 17 patients $(52 \%)$ remained unchanged, and that of 2 patients $(6 \%)$ worsened. Eight patients were in class I after the operation. Three patients died of intractable heart failure with ventricular tachyarrhythmia, but no patients died of sudden arrhythmia without heart failure. No implantable defibrillator was used. According to Holter monitoring, $42 \%$ of the patients had an improvement in NYHA class after the operation, and ventricular arrhythmia improved significantly $(P<.0017)$.

According to the Cox proportional hazards model analysis for hospital and late mortality, the factors influencing the surgical results were severe mitral regurgitation, preoperative NYHA functional class IV with the need for emergency treatment, and a randomly performed PLV without intraoperative echocardiography $(P<.05)$, as summarized in Table III.

\section{Discussion}

Although medical treatment is advancing for heart failure ${ }^{7-9}$ many patients are still awaiting cardiac transplantation. As physicians try to find an effective nontransplant cardiac surgical procedure, PLV, ${ }^{1,2,10-13}$ EVCPP, ${ }^{3}$ cardiomyoplasty, ${ }^{14,15}$ and the ventricular assist device ${ }^{16-18}$ have been applied clinically, in addition to valvular reconstruction or CABG.

Whereas Batista and colleagues ${ }^{1}$ have applied PLV for ischemic cardiomyopathy, we prefer EVCPP. Exclusion of akinetic septum, which is frequently associated with ischemic cardiomyopathy caused by occlusion of the large anterior descending artery, is easy and effective with the use of the purse-string suture technique described by Fontan. ${ }^{19}$ Dreyfus and colleagues ${ }^{20}$ have shown that CABG alone is effective in a certain group of patients assessed by positron emission tomography and several preoperative examinations. However, Yamaguchi and associates ${ }^{21}$ performed CABG alone in 41 patients with an ischemic dilated heart. They suggested that the preoperative left ventricular end-systolic volume index predicted the development of postoperative congestive heart failure and actuarial survival in patients with ischemic cardiomyopathy. In our series, preoperative left ventricular viability was not always fully evaluated because of the patient's condition and lack of a positron emission tomographic scan. However, we believe that the combination of an enlarged left ventricle, signs of heart failure, and absence of angina pectoris are strong indicators of an unsuccessful outcome by CABG alone. ${ }^{21}$ We think that surgical restoration is an effective solution for a better outcome. ${ }^{22}$

The surgical strategy for nonischemic cardiomyopathy is more complicated. In the beginning, we thought that the extent of myocardial damage was homogeneous in idiopathic cardiomyopathy; therefore, we simply followed Batista's PLV to make the enlarged left ventricle small. After our initial experiences looking inside the left ventricle, we found that the area that was supposed to have pronounced endocardial scarring did not have macroscopic scars. This evidence was proven by pathologic findings obtained from excised posterior wall and remaining septum in the same heart in our specimens. Therefore, we decided that it was important to assess the left ventricular wall characteristics before PLV to avoid excessive resection of a kinetic area. Intraoperative evaluation by echocardiography was found to be helpful for this purpose.

The next important problem was the return of intractable heart failure, which probably was due to (1) 
Preoperative
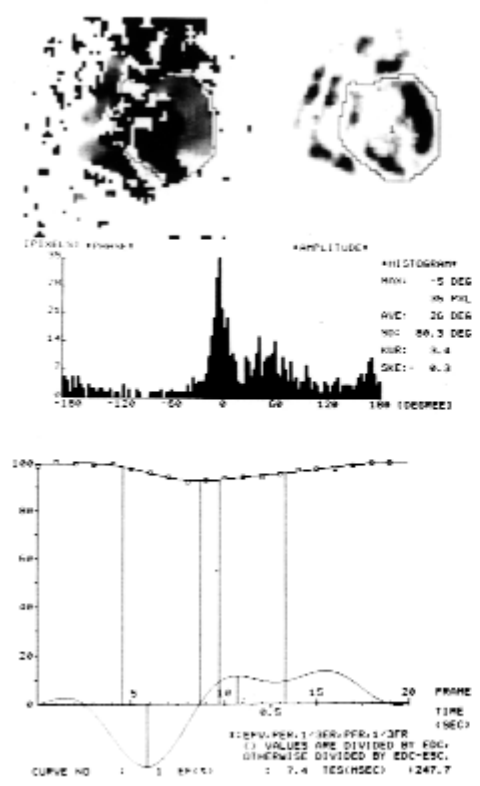

EF

$7.4 \%$
Postoperative 1 month
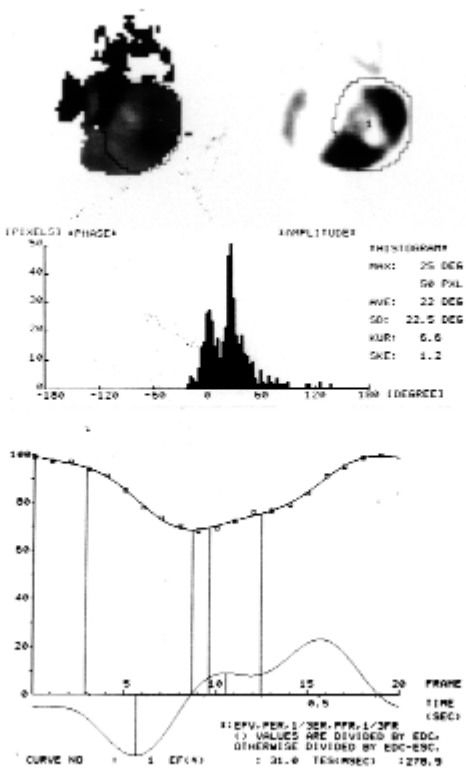

$31.0 \%$
Postoperative 6 months
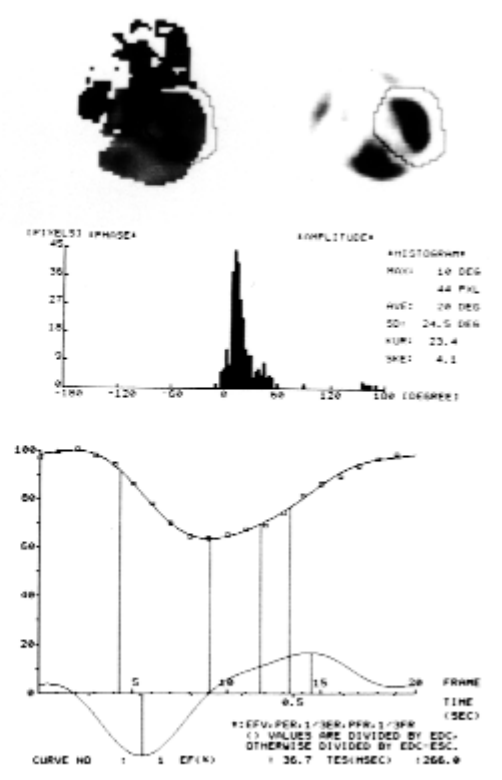

$36.7 \%$

Fig 8. Phase-image analysis in gated cardiac radioimmunologic scintiscan before and after partial left ventriculectomy. No valve reconstruction was combined because the patient did not have significant mitral regurgitation. Ejection fraction $(E F)$ increased from $7 \%$ to $31 \%$ and $37 \%$ at 1 and 6 postoperative months. Histogram showed improved synchronicity with decreased SD from 80.3 to 22.5 and 15.6 after the operation. New York Heart Association class improved from IV to I in a 38-year-old man.

recurrence of mitral regurgitation, (2) a remaining dilated lesion of the left ventricle, (3) too small a left ventricle due to excessive excision, and (4) removal of the kinetic left ventricular wall without removal of lesions.

Prediction of the appropriate postoperative left ventricular size is difficult because a proper size depends on myocardial stiffness, and the stiffness is different in each patient with cardiomyopathy. ${ }^{23,24}$ For example, a postoperative left ventricular diameter below $6 \mathrm{~cm}$ is good for a low-stiffness ventricle, but it is too tight for a high-stiffness ventricle and easily results in a diastolic disorder. Therefore, a theoretic model ${ }^{25,26}$ is difficult to devise as an experimental model to decide the correct degree of left ventricular reduction.

After proper selection of operative procedures, hospital mortality and morbidity and late death decreased significantly. Because the kinetic left ventricular muscle was left intact, the prevalence of congestive heart failure lessened. When PLV was being performed nonselectively, heart failure was caused by making the heart too small or by excision of kinetic heart muscle. Medical treatment after such inappropriate procedures was difficult.
According to Bolling and colleagues, ${ }^{4}$ mitral reconstruction can be performed alone for cardiomyopathy with significant mitral regurgitation, with a low operative mortality, although there is a risk of late death and return of heart failure within 4 years after the operation. The 2-year actuarial survival in their report was $71 \%$. This late morbidity is higher in the ischemic group than the nonischemic group. Therefore, we thought this procedure might work in a certain type of nonischemic cardiomyopathy in which mitral regurgitation is causing left ventricular dilatation with viable myocardium.

By intraoperative echocardiographic assessment, 13 of 29 patients with a dilated left ventricle associated with mitral regurgitation were thought to be acceptable for this procedure. The mortality was low with valve surgery alone, but late follow-up was needed to see whether the incidence of recurrent heart failure was reduced or not. In our experience, 2 patients with initial mitral valve reconstruction have undergone left ventricular reduction because of recurrent heart failure. With careful follow-up of patients and analysis of the results, the decision of whether to perform left ventricular reduction or valvular 

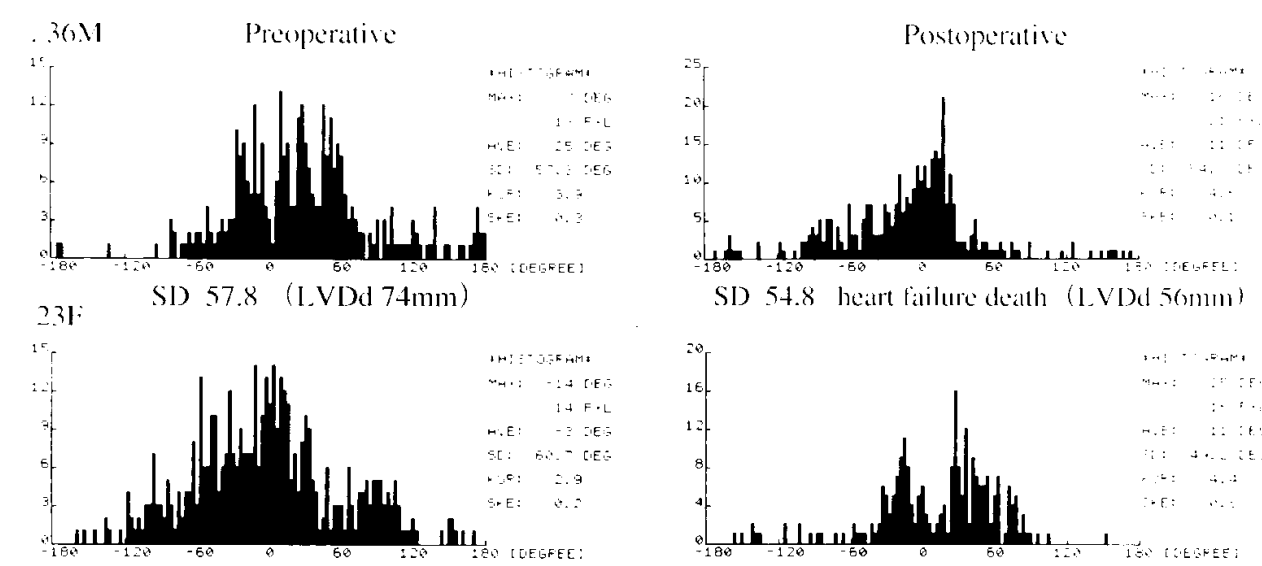

SD 54.8 heart failure death (L.VDd $5(\mathrm{mmm})$

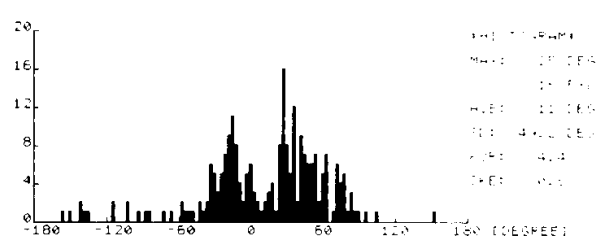

SD 49.2 hearl failure death (L.VDd $5.3 \mathrm{~mm})$
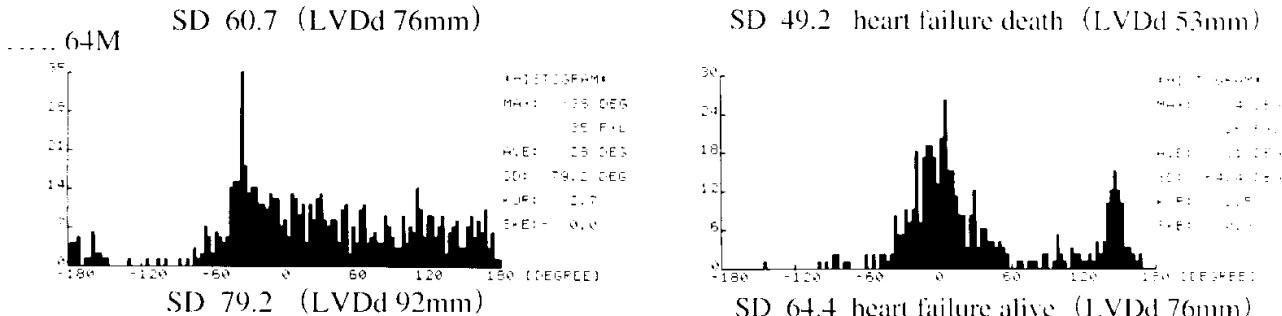

SD $0+.4$ hearl failure alive (L.VD) 7 (onm)

Fig 9. Phase-image analysis in patients who had return of heart failure after partial left ventriculectomy. They were all discharged once with clinical improvement. Note that the postoperative left ventricular diameter $(L V D d)$ is not always too large.

Table III. Cox proportional hazard model analysis for hospital and late mortality

\begin{tabular}{|c|c|c|c|c|}
\hline Variable & No. & Hazard ratio & $95 \% C L$ & $\mathrm{P}$ value \\
\hline \multicolumn{5}{|l|}{ Sex } \\
\hline Female & 12 & 1 & & \\
\hline Male & 74 & 0.61 & $0.23-1.61$ & .3 \\
\hline \multicolumn{5}{|l|}{ Mitral regurgitation } \\
\hline Absent & 23 & 1 & & \\
\hline Present & 63 & 3.34 & $1.00-11.14$ & .050 \\
\hline \multicolumn{5}{|l|}{ NYHA } \\
\hline III & 37 & 1 & & \\
\hline IV & 49 & 3.09 & $1.24-7.69$ & .02 \\
\hline \multicolumn{5}{|l|}{ Operation } \\
\hline Elective & 72 & 1 & & \\
\hline Emergency & 14 & 7.17 & $3.20-16.08$ & $<.001$ \\
\hline \multicolumn{5}{|l|}{ Procedure } \\
\hline EVCPP \pm valve & 33 & 1 & & \\
\hline Group I & 24 & 2.70 & $1.12-6.53$ & .03 \\
\hline Group II: LV reduction & 16 & 0.27 & $0.03-2.20$ & .2 \\
\hline Group II: Valve alone & 13 & 1.27 & $0.38-4.22$ & .7 \\
\hline \multicolumn{5}{|l|}{ Age (y) } \\
\hline $14-49$ & 29 & 1 & & \\
\hline $50-61$ & 31 & 0.94 & $0.38-2.33$ & .9 \\
\hline $62-74$ & 26 & 0.79 & $0.29-4.22$ & 6 \\
\hline \multicolumn{5}{|l|}{ Ejection fraction (\%) } \\
\hline $4-19$ & 34 & 1 & & \\
\hline $20-25$ & 27 & 0.67 & $0.28-1.62$ & .4 \\
\hline $26-33$ & 22 & 0.40 & $0.13-1.24$ & .11 \\
\hline
\end{tabular}

$C L$, Confidence limits; NYHA, New York Heart Association; EVCPP, endoventricular circular patch plasty; $L V$, left ventricular; group I, before induction of volume reduction test; group II, after induction of volume reduction test. 
reconstruction alone will be made more accurately in the future.

One useful diagnostic method to predict recurrent heart failure was a histogram of phase image analysis in gated cardiac radioimmunologic scintigraphy. Phase image analysis is known to be a reliable method to assess the function and conduction of the left ventricle. ${ }^{27,28}$ In all examined patients with cardiomyopathy, the histogram showed a widespread standard deviation due to lack of synchronicity of the left ventricle. Therefore, cautious follow-up was necessary and reoperation or listing for cardiac transplantation was advisable for those patients with clinical improvement after the operation but no improvement in the histogram.

\section{Conclusion}

1. Ventriculoplasty and valvuloplasty are acceptably safe and effective treatments for end-stage cardiomyopathy with the proper choice of patients and surgical procedures.

2. In emergency operations for patients with ongoing shock, PLV is associated with an extremely high risk. Treatment with a left ventricular assist device, if available, should be considered initially.

3. An echo-guided volume reduction test provides vital ventricular wall characteristics.

4. Phase image analysis is useful to predict the recurrence of heart failure.

\section{REFERENCES}

1. Batista RJV, Verde J, Nery P, Bocchino L, Takeshita N, Bhayana $\mathrm{JN}$, et al. Partial left ventriculectomy to treat end-stage heart disease. Ann Thorac Surg 1997;64:634-8

2. McCarthy PM, Starling RC, Wong J, Scalia GM, Buda T, Vargo RL, et al. Early results with partial left ventriculectomy. J Thorac Cardiovasc Surg 1997;114:755-63.

3. Dor V, Sabatier M, Di Donato M, Montiglio F, Toso A, Maioli M. Efficacy of endoventricular patch plasty in large postinfarction akinetic scar and severe left ventricular dysfunction: comparison with a series of large dyskinetic scars. J Thorac Cardiovasc Surg 1998;116:50-9.

4. Bolling SF, Pagani FD, Deeb GM, Bach DS. Intermediate-term outcome of mitral reconstruction in cardiomyopathy. J Thorac Cardiovasc Surg 1998;115:381-6.

5. Dor V. Reconstructive left ventricular surgery for postischemic akinetic dilatation. Semin Thorac Cardiovasc Surg 1997;9:13945.

6. Torrent-Guasp F. A silicone rubber mould of the heart. Technol Health Care 1997;5:13-20.

7. Heidenreich PA, Lee TT, Massie BM. Effect of beta-blockade on mortality in patients with heart failure. J Am Coll Cardiol 1997;30:27-34

8. Parker MO, Connor CM, Ghali JK, Presler ML, Carson PE, Belkin RN, et al. Effect of amlodipine on morbidity and mortality in severe chronic heart failure. $N$ Engl J Med 1996;335:1107-14.
9. Singh SN, Fletcher RD, Fisher SG, Singh BN, Lewis HD, Deedwania PC, et al. Amiodarone in patients with congestive heart failure and asymptomatic ventricular arrhythmia. N Engl J Med 1995;333:77-82.

10. Angelini GD, Pryn S, Mehta D, Izzat MB, Walsh C, Wilde P, et al. Left-ventricular-volume reduction for end-stage heart failure. Lancet 1997;350:489.

11. Moreira LFP, Stolf NAG, Bocchi EA, Bacal F, Giorgi MCP, Parga JR, et al. Partial left ventriculectomy with mitral valve preservation in the treatment of patients with dilated cardiomyopathy. $\mathrm{J}$ Thorac Cardiovasc Surg 1998;115:800-7.

12. Suma H, Isomura T, Horii T, Sato T, Kikuchi N, Iwahashi K, et al. Two-year experience of the Batista operation for non-ischemic cardiomyopathy. J Cardiol 1998;32:269-76.

13. Gradinac S, Miric M, Popovic Z, Popovic A, Neskovic A, Jovovic $\mathrm{L}$, et al. Partial left ventriculectomy for idiopathic dilated cardiomyopathy: early results and six-month follow-up. Ann Thorac Surg 1998;66:1963-8.

14. Magovern GJ, Simpson KA. Clinical cardiomyoplasty: review of the ten-year United States experience. Ann Thorac Surg 1996;61:413-9.

15. Chachques JC, Grandjean P, Schwarz K. Effect of latissimus dorsi dynamic cardiomyoplasty on ventricular function. Circulation 1988;78:(Suppl):III-203-16.

16. Lewin HR, Oz MC, Chan JM, Packer M, Rose EA, Burkhoff D. Reversal of chronic ventricular dilation in patients with end-stage cardiomyopathy by prolonged mechanical offloading. Circulation 1995;91:2717-20.

17. Frazier OH, Benedict CR, Radovancevic B, Bick R, Capek P, Springer WE, et al. Improved left ventricular function after chronic left ventricular offloading. Ann Thorac Surg 1996;62:675-82.

18. Westaby S, Jin XY, Katsumata T, Taggart DP, Coats AJS, Frazier $\mathrm{OH}$. Mechanical support in dilated cardiomyopathy: signs of early left ventricular recovery. Ann Thorac Surg 1997;64:1303-8.

19. Fontan F. Transplantation of knowledge. J Thorac Cardiovasc Surg 1990;99:387-9.

20. Dreyfus GD, Duboc D, Blasco A, Vigoni F, Dulas C, Dubois C, et al. Myocardial viability assessment in ischemic cardiomyopathy: benefits of coronary revascularization. Ann Thorac Surg 1994;57:1402-7.

21. Yamaguchi A, Ino T, Adachi H, Murata S, Kamio H, Okada M, et al. Left ventricular volume predicts postoperative course in patients with ischemic cardiomyopathy. Ann Thorac Surg 1998;65:434-8.

22. Buckberg GD. Defining the relationship between akinesia and dyskinesia and the cause of left ventricular failure after anterior infarction and reversal of remodeling to restoration. $\mathrm{J}$ Thorac Cardiovasc Surg 1998;116:47-9.

23. Gorcsan J III, Feldman AM, Kormos R, Mandarino WA, Demelris AJ, Batista RJV. Heterogeneous immediate effects of partial left ventriculectomy on cardiac performance. Circulation 1998;97:839-42

24. Kawaguchi A, Sugimachi M, Ishibashi-Ueda H, Ujiie T, Koide S, Batista RJV. Limited preload reserve and milder myocardial fibrosis favors partial left ventriculectomy. Circulation 1998;98:(Suppl):I-829.

25. Ratcliffe MB, Hong J, Salahieh A, Ruch S, Wallace AW. The effect of ventricular volume reduction surgery in the dilated, poorly contractile left ventricle: a simple finite element analysis. J Thorac Cardiovasc Surg 1998;116:566-77. 
26. Dickstein ML, Spotnitz HM, Rose EA, Burkhoff D. Heart reduction surgery: an analysis of the impact on cardiac function. $\mathrm{J}$ Thorac Cardiovasc Surg 1997;113:1032-40.

27. Botvinick E, Dunn R, Frais M, O’Connell W, Shosa D, Herfkens $\mathrm{R}$, et al. The phase image: its relationship to patterns of contraction and conduction. Circulation 1982;65:551-60.

28. Frais M, Botvinick E, Shosa D, O'Connell W, Alvarez JP, Dae M, et al. Phase image characterization of localized and generalized left ventricular contraction abnormalities. J Am Coll Cardiol 1984;4:987-98.

\section{Discussion}

Dr Steven F. Bolling (Ann Arbor, Mich). This paper continues Dr Suma's good work in geometric restoration of the left ventricle. Many procedures are being developed in that area. This paper helps us to make a better choice of which patient will do well. I have a number of questions for you, Dr Suma.

It is clear that this is a mixed series and that you changed the type of operation, the type of patient, and even how the operations were performed. Do you think this is reflective of the learning curve, and do you have these procedures now crystallized in your mind on how we should all do them?

Second, did you undersize all the mitral rings, as is being advocated by some? Did all of the patients with mitral regurgitation have $4+$ regurgitation?

We would all like to be able to predict which patients will do well with a given operation, and this manuscript addresses those concerns. In terms of your volume size test on CPB, how thick should the myocardium be? Is there a measurement in millimeters that we should leave in or take out depending on how thick the myocardium is? How kinetic is kinetic? Is there an area of dyskinesia that we should leave in hopes that it will recover, or should we take it out? How do you evaluate diastolic function during decompressed CPB? How stiff is too stiff?

Last, myocyte size and fibrosis are not predictive of outcome. Were there other markers, perhaps biochemical markers or neurohormonal markers, that could be used to predict patient outcome?

Dr Suma. Thank you very much, Dr Bolling. To answer your question about procedure change, it certainly was a result of the learning period. I learned a lot in treating 20 to 30 patients. As you know, when the Batista operation was first introduced, the idea was simply to make the big heart small, with no knowledge of viability or extent of myocardial disease. It was like jumping into the jungle without a map. Certainly, we have to jump into the jungle to save the patient with heart failure, but we do need a reliable map.

Today I mentioned our map, which is still primitive. However, if we make many maps and put them together, I think this operation will grow. During the first period in nonischemic dilated cardiomyopathy, I found that the extent of myocardial disease is not homogeneous. Sometimes part of the posterior wall is diseased, and sometimes part of the septum. We have to know the extent of the lesion and viability before selecting the procedure. Therefore, we introduced the intraoperative echo-guided volume reduction test as a sort of viability provocation.

It is impossible to know the actual thickness of the left ventricular wall before the operation, because most of the left ventricular wall of dilated hearts looks very thin by echocardiography. For one thing, it is already fibrotic or just stretched, but we cannot tell the difference unless we reduce wall tension. Fortunately, we can do it during the operation by left ventricular decompression on the pump, and we can have the information before we cut the left ventricle. Then we can decide whether to do an annuloplasty alone or whether to cut somewhere. We always try to insert an undersized ring to stop mitral regurgitation, as you suggested, regardless of the degree, not only 4+ regurgitation.

Once we identify the akinetic or dyskinetic area with left ventricular decompression, we believe this area should be excised or excluded. However, it is important not to make the heart too small.

The Dor operation is the primary choice for ischemic cardiomyopathy. In ischemic cardiomyopathy, which mostly results from occlusion of the left anterior descending artery, the septum is almost always involved. It is advisable to exclude it, and patch plasty is an effective and easy way.

Diastolic function is a very difficult problem but very important. We tried to identify this by the peak filling ratio or by a time to peak filling by using postoperative radioimmunoassay scintigraphy. We found a slight trend to indicate that diastolic function gets better in patients who return to NYHA class I or II and that it gets worse in patients who have recurrent heart failure. However, the number is small; I cannot tell you the final answer.

We could not find any correlation to clinical outcome by looking at myocytes. A Brazilian group, however, has previously shown that myocytes are an important predictor. We still do not know much about it, and we do not have any other marker to predict the outcome at present.

Dr Patrick M. McCarthy (Cleveland, Ohio). This is an interesting and unique report from Dr Suma, because he describes a variety of operations for a heterogeneous group of patients with cardiomyopathy. Since the paper includes such diverse problems as sarcoidosis-induced cardiomyopathy and arrhythmogenic right ventricular dysplasia, as well as unusual operations such as left ventricular assist device implantation with tricuspid valve replacement, it is easy to overlook some of the important fundamental messages.

The first message is that for elective operations, the mortality was very low; it was $4 \%$ for the Dor procedure, $6 \%$ for the Batista operation, and $0 \%$ for valve surgery. Second, short-term and mid-term clinical follow-up and left ventricular function follow-up showed significant improvement. Thus, the message is that for patients in stable condition undergoing elective operations, a variety of interventions can be safely performed with good initial results. Our job is to learn how best to apply a variety of operations to a diverse group of patients with cardiomyopathy.

I have 3 questions. First, in the patients with nonischemic dilated cardiomyopathy with localized thinning that you see 
by intraoperative echocardiography, how do you handle the thin-walled left ventricular septum?

Second, does the long-term management of these patients postoperatively include intensive heart failure treatment such as angiotensin-converting enzyme inhibitors, carvedilol, and amiodarone? Do you give warfarin sodium (Coumadin) to these patients with left ventricular reconstruction?

Third, the data on peak filling ratio were intriguing, indicating diastolic dysfunction in the patients in whom heart failure recurred. Do you have preoperative peak filling data that might help to predict which patients will not be benefited by surgery?

Dr Mehmet C. Oz (New York, NY). Dr Suma, excellent results such as those that you present have captured the imagination of many of the surgeons in the audience. They have not done the same for our referring cardiologists, and part of their criticism revolves around our definition of what "improvement" means.

In addition to ejection fraction, which many in the cardiology group do not acknowledge to indicate improvement, do we have hemodynamic indexes or other evidence of true improvement in the ventricular function of these patients over the long term, including everything from pressure volume loops to evaluations of wall thickness? You seem to have the imaging ability to get this information.

Apropos of the need to convince our referring physicians that there is something to this operation, or this range of operations, do we need a randomized trial, either between medical therapy and the Dor procedure, or perhaps even within a surgical group, to decide whether patients should be getting just CABG or valve repair with or without a Dor-type operation?

Dr Suma. Dr McCarthy, you raised a very important technical point. In the beginning we thought that muscle damage was almost homogeneous in the nonischemic dilated cardiomyopathy, but it is not. If the patient has a diseased area in the septum and anterior myocardium and the surgeon per- forms the typical Batista operation, which excises the lateral wall, then the patient will die. In this particular case, it would be preferable to do the EVCPP to exclude the anterior myocardium and septum. But it is important to be careful. In nonischemic disease, the muscle is fragile, and it is not easy to insert the purse-string stitch and put the patch on. The surgeon must think about a different technique, perhaps an interrupted stitch, to fix the patch. We have done this in 3 patients with nonischemic cardiomyopathy, and all are alive and well, so far.

To answer the second question, we continue to use the angiotensin-converting enzyme inhibitor, carvedilol, and amiodarone after the operation. Interestingly, in some cases we found that those drugs are easier to use after the operation.

Finally, I do not have any data regarding use of diastolic function as a preoperative parameter to predict outcome, because it is very variable. Until we understand the diastolic function more clearly, it will be difficult to make it a single predictor for outcome.

Dr Oz, ejection fraction provides no information to help the cardiologists understand how the patient gets better. The most striking parameter is clinical status. We often see that the ejection fraction rose $5 \%$ but the patient's clinical status has risen from class IV to class II or I. Pressure volume loop, cardiac output, and the oxygen consumption are also important parameters.

It was impossible to conduct a randomized trial because at the time of this study we could not reliably predict good results with left ventricular reduction. Now the situation has stabilized. If someone wants to conduct a randomized trial now, it may be possible to do it. However, it seems to be really difficult to randomize for the experts. If you send the patient to Dr Dor, he may always do the Dor operation. If you send the patient to $\mathrm{Dr}$ Bolling, he may never touch the left ventricle. It may be that a randomized trial can be done only by someone else, who can learn every technique at a high level. 